\title{
New type of tsunami barrier
}

\author{
Hans J. Scheel
}

Received: 1 November 2012/Accepted: 13 August 2013/Published online: 6 September 2013

(C) The Author(s) 2013. This article is published with open access at Springerlink.com

\begin{abstract}
Tsunami impact on a coast can be reduced by applying a submerged vertical barrier to reflect tsunami before the catastrophic waves are built up near the coast. However, construction of such long walls by conventional submarine technology is difficult. In this paper, the construction of extended submarine walls at a depth of between 50 and $500 \mathrm{~m}$ below sea level by a relatively simple and efficient technology is described. The submarine walls can consist either of high-strength steel fences with anchors or two parallel steel fences with distance holders, lowered into the sea and fixed with rocks inserted from top. Alternatively, the barriers could be built from gabions (prefabricated steel net baskets filled with rocks) and lowered into the sea. The space between these tsunami barriers and the coast can be filled with solid material, thus allowing reclamation of new land, or this gap can be used for fish farming. These barriers can contribute to preservation of beaches and natural ecosystems at the coast.
\end{abstract}

Keywords Tsunami barriers · Tsunami protection - Submarine architecture $\cdot$ Deepsea walls $\cdot$ Land reclamation $\cdot$ Flooding protection $\cdot$ Fish farming

\section{Introduction}

A general description of tsunamis can be found in Bryant (2008), and Strusinska (2011) reviewed the literature of tsunami investigations including computer simulations using the Coulwave programme of Lynett and Liu (2011). The development of tsunami waves from pressure waves, the overtopping over breakwaters and the runup into the land have been extensively studied. The life and effectivity of protective dams and walls against storms and tsunami waves are limited due to high flow velocities and the impact of the waves, 
because these dams are built near the coast. A critical discussion of numerous coastal structures and their hydraulic stability (tilting, sliding) was given by Burcharth and Hughes (2002, 2011) and also discussed by Strusinska (2011).

Expensive tsunami warning systems have been introduced, and Annunziato et al. (2012) have discussed the improvements of the Global Disasters Alerts and Coordination System with the analysis of the Tohoku earthquake and Tsunami of 11 March 2011. In case of early warning, the coastal population can try to reach higher altitude, but severe damages cannot be prevented.

In the following, a tsunami protection system will be described which effectively will save human lives and avoid material damages by preventing the formation of tsunami waves (Scheel 2012, 2013a, b). This is achieved by a stable vertical barrier built at a water depth below $50 \mathrm{~m}$, which reflects the pressure (or gravitation) waves from earthquakes or landslides before the catastrophic tsunami can develop.

\section{Principle and possible applications of new type of tsunami barrier}

The working principle of the vertical deep barrier is shown in Fig. 1. The pressure waves originating from earthquakes and landslides are reflected at the stable wall and then propagate back into the ocean (Scheel 2012). If one considers the variation of the wave velocity and the related amplitude development during the movement towards the coast, that is during experiencing decreasing water depth, one realizes that the high tsunami sea waves develop only at water depth less than about $500 \mathrm{~m}$ or even $200 \mathrm{~m}$. Their velocity $c$ is given in a first approximation (Levin and Nosov 2009 Ch. 1.1 and Ch. 5.1) by

$$
c=\sqrt{ }(g \times h)
$$

with $g$ gravitational acceleration and $h$ the water depth. The product of the amplitude or wave height $A$ squared and velocity $\boldsymbol{c}$ is constant:

$$
A^{2} \times c=\text { constant. }
$$

These relations are shown in the combined Fig. 2 with the parameters $c=713 \mathrm{~km} / \mathrm{h}$ at a water depth of $4,000 \mathrm{~m}$ for two typical examples of wave heights of $A_{1}=0.3 \mathrm{~m}$ and $A_{2}=1.0 \mathrm{~m}$ at $h=-4,000 \mathrm{~m}$. The lower part of the figure shows the velocity $\mathrm{c}$ as function of water depth $\mathrm{h}$ with an idealized profile of the continental shelf with a slope increasing near the "break". The upper part of the figure shows the wave height A as a

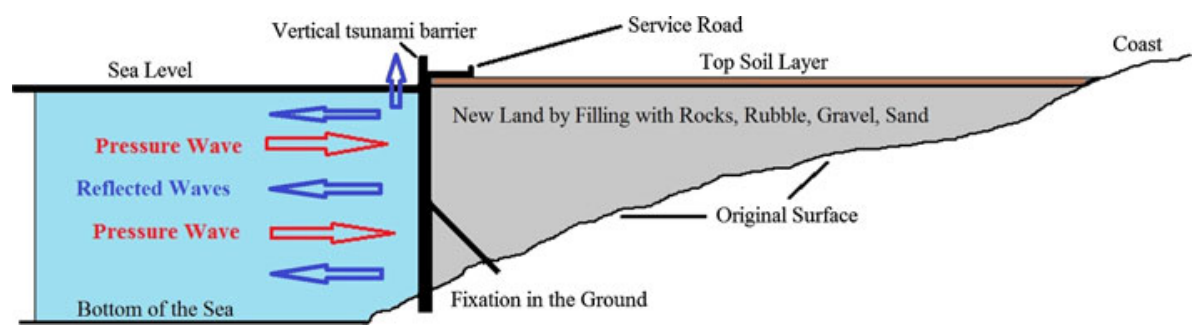

Fig. 1 Schematic cross section of a vertical tsunami barrier reflecting the pressure waves. The space towards the coast is filled in order to gain new land 
function of water depth $\mathrm{h}$. The tsunami wave heights increase slightly until water depth is less than about $500 \mathrm{~m}$, and only at water depth around $200 \mathrm{~m}$, the wave heights increase above $2 \mathrm{~m}$ for initial wave heights of 0.3 and $1.0 \mathrm{~m}$ at $4 \mathrm{~km}$ water depth. This indicates that the tsunami barrier can be erected at water depth between 50 and $500 \mathrm{~m}$ which is still above the continental shelf. With a tsunami barrier up to $3 \mathrm{~m}$ above sea level at high tide and a top concrete wall extending 6-8 $\mathrm{m}$ above the top of the tsunami barrier, depending on highest expected tsunami/storm waves, the combined submerged tsunami barrier and the top concrete wall with the surge stopper should be effective to protect the coast. This novel technology prevents high tsunami waves, whereas prior art breakwaters are designed to reduce the catastrophic effect of high tsunami waves near the coast after these waves have been formed.

The prominent example is the world's deepest breakwater of Kamaishi which was built over the period of 31 years at the cost of 1.5 billion USD to protect Kamaishi city and harbour in Iwate Prefecture, Japan. However, with its depth of $63 \mathrm{~m}$ and length of $2 \mathrm{~km}$, it did not protect Kamaishi from the March 2011 Tohoku Tsunami so that 1,250 people were killed, and city, harbour and even the dam were partially destroyed (Onishi and Norimitsu 2011).

Also it should be considered that deviations from the straight coastline like bays (the example of Kamaishi) or fjords may lead to a funnel effect which can multiply the heights of tsunami waves reaching the coast. In contrast, the new tsunami barrier is remote from the shore so that the funnel effect of bays and fjords is prevented.

These reflected pressure waves can be harmful at the opposite distant coast so that a slight inclination from vertical should be applied to reflect the wave downward in the case of north-east Honshu/Japan coast into the Japan trench in the Pacific Ocean. Or the inclination should be slightly upward to transform the kinetic energy of the pressure wave into potential energy by formation of dispersed sea waves moving away from the coast. A

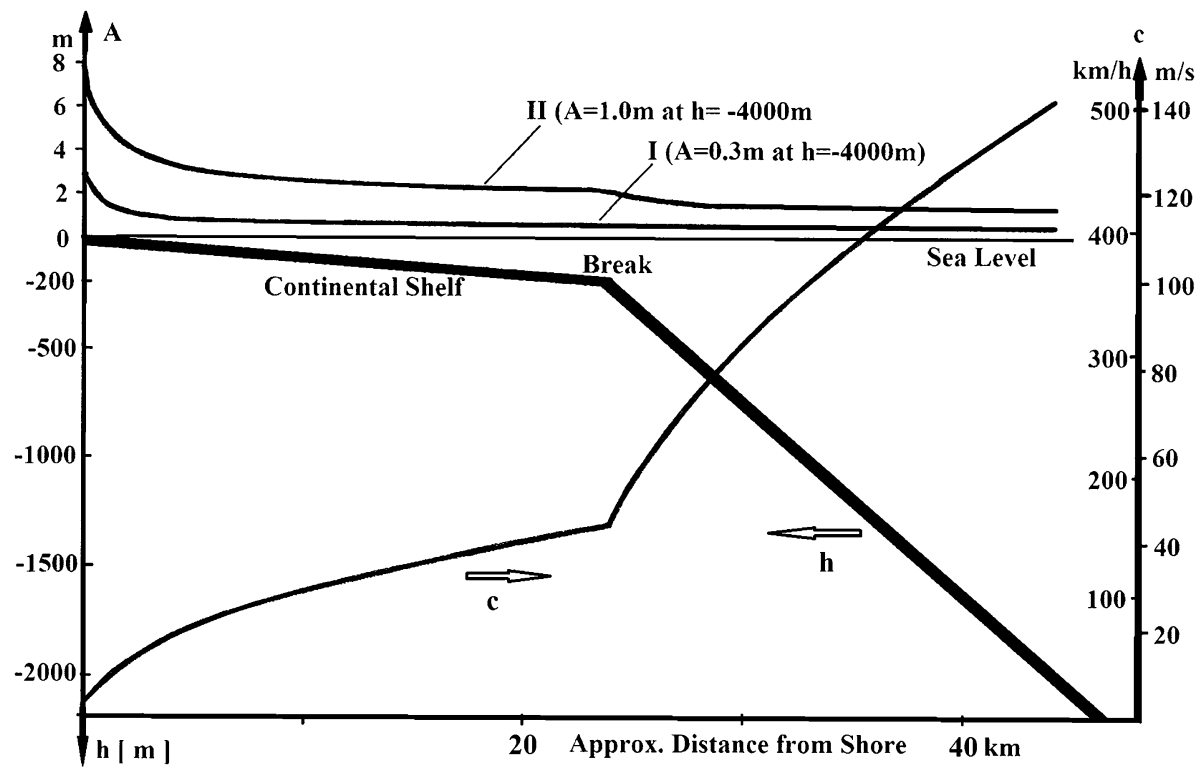

Fig. 2 Schematic cross section of sea ground with break of continental shelf and dependence of wave velocity $c$ on water depth $h$ (lower section) and on wave height $A$ (upper section) 
fraction of the initial energy of the pressure wave will be released upward so that some volume of sea water will rise in front of the tsunami barrier. On top of the tsunami barrier, a concrete vertical wall can be built with a height depending on the highest expected storms waves and on the volume of the uprising sea in the rare case of arriving pressure waves (Scheel 2012).

Steel beams on the top of this vertical wall enable a later increase in the wall height and can also be used to hang inclined elements of concrete or other stable material seaward, to prevent or at least reduce the overtopping of the highest waves, to protect the vertical concrete wall, and to protect the new land. These triangular elements of 1-5 m horizontal length are transported along the service road and can be replaced after erosion, also for testing different construction materials (Scheel 2012).

Figure 1 shows also the possibility to reclaim new land if the space between the tsunami barrier is filled with rocks, gravel and soil on top. Gaining of new land may partially compensate the high costs of building the tsunami barriers. Here, the distance between the barrier and the coast is large - tens of $\mathrm{km}$, depending on the slope of the seabed, so that the filling requires huge masses of rocks and rubble.

A terrace structure of tsunami barriers reduces the total amount of filling material as shown in Fig. 3 (Scheel 2012). These tsunami barriers are constructed parallel to the coast as a continuous steel fence with attached anchors, which extend 5-20 m horizontally towards the coast (Scheel 2012), see Fig. 3. By subsequent introducing cleaned rocks with sharp edges and controlled size, the anchors and thus the fences get fixed. Increased stability is achieved by lowering gravel onto the rocks and by covering the rocks periodically with horizontal steel fences or by concrete. The seabed and the rocks are cleaned before from sand and soft deposits in order to allow observation of the process by illumination and video cameras, by divers, by remotely operated vehicles ROV (Elwood et al. 2004; Tarmey and Hallyburton 2004) or by autonomous underwater vehicles (Bingham et al. 2002; WHOI 2012). An alternative tsunami barrier can be built as two parallel steel fences of which the distance of 3-20 m is kept by distance holders from steel. Rocks are inserted into this fence/basket from two pontoons held at constant distance.

The barrier can also be built from prefabricated steel baskets (gabions), transported to the site in the sea, filled with rocks and lowered into the sea. These baskets are of cube or rectangular or other space-filling shape and have been used on ground for protecting river banks, for military (Hesco bastion) and for wall construction (Modular Gabion Systems 2013). Further rocks and other solid material like concrete blocks or rubble can be deposited on the landward side of the tsunami barrier in order to increase the stability against the pressure waves.

A variety of steel wire fences of high flexibility and strength have been developed by GEOBRUGG (2012) for protecting roads and railway from falling stones and avalanches.

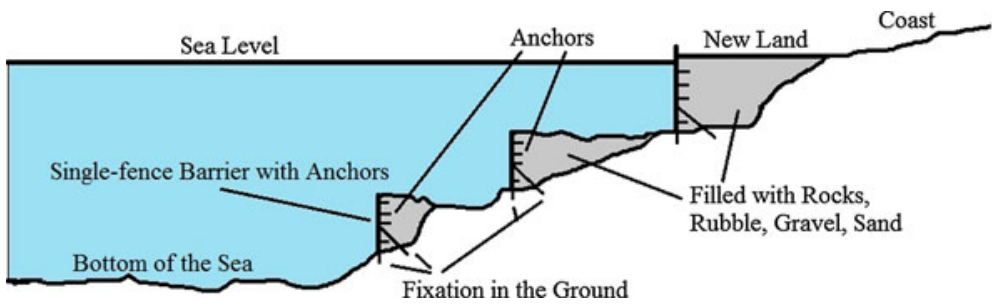

Fig. 3 Schematic cross section of terrace with three vertical tsunami barriers 
For the new application to the tsunami barriers, special saltwater-corrosion-resistant steels have to be used, for example chromium- and molybdenum-containing low-carbon steels with European numbers 1.4429 (ASTM316LN), 1.4462, 1.4404 or 1.4571(V4A). All alloy parts should have the same composition in order to prevent electrolytic corrosion at the contacting points. For galvanized normal steel, the life of 60 years in the sea has been reported. Thus, an extended life can be expected when using special stainless steel, especially if it is coated by an elastic polymer or covered by a layer of concrete. With sufficient stabilization by horizontal fences or concrete, the rock structure itself would remain intact even if the steel fence would corrode after hundreds of years. Also, it would be possible to add a new fence and fix it to the horizontal anchors.

The top concrete walls with hanging inclined structures will be beneficial against the impact of tsunami and highest storm waves when wall height is at least comparable to the height of the arriving waves. The structure allows later heightening with rising sea level and replacement of the hanging protecting structures.

\section{Conclusions}

A new technology for submarine architecture is based on high-stability steel fences or baskets which are fixed by rocks inserted from the top. This method allows to build long submerged tsunami barriers parallel to the coast. These barriers reflect the pressure waves from earthquakes and landslides before the catastrophic high tsunami waves are formed. The high construction costs may partially be compensated by advantages derived from land reclamation or from fish farming in large regions of the sea.

The realization of such tsunami barriers requires the development of special ships and pontoons for inserting the steel fences, steel baskets and the rocks, the arrangement of harbours for their stationing, the production of corrosion-resistant steel wires and factories for steel fence and basket production.

This early communication is meant to inform governments of countries prone to tsunami risk as well as insurance companies about the possibility of protecting threatened cities, airports, nuclear power stations, harbours and popular beaches from the next large tsunami and from tidal waves. Such national projects would stimulate industries and provide occupation for many people.

Acknowledgments The author thanks Dr. A. Strusinska for critical reading the manuscript.

Open Access This article is distributed under the terms of the Creative Commons Attribution License which permits any use, distribution, and reproduction in any medium, provided the original author(s) and the source are credited.

\section{References}

Annunziato A, Franchello G, De Groeve T (2012) Response of the GDACS System to the Tohoku Earthquake and Tsunami of 11 March 2011. Sci Tsunami Hazards 31:283-296

Bingham D, Drake T, Hill A and Lott R (2002), The application of autonomous underwater vehicle (AUV) technology in the oil industry-vision and experiences. FIGXXII Int.Congr. Wash. D.C. 19-26

Bryant E (2008) Tsunami, the underrated hazard, 2nd edn. Springer/Praxis Publ Ltd, Chichester UK

Burcharth HF, Hughes SA $(2002,2011)$ types and functions of coastal structures in coastal eng manual, Chapter 2: US Army Corps of Eng. Rep. EM 1110-2-1100 Part VI (30 April 2002; Change 3, 28 Sept. 2011) 
Elwood NJ, Coviello CW, Scott IV HC (2004) Commercial engineer divers: an underwater window. Sea Technol Mag 45(12):35-38

Geobrugg (2012) Geohazard solutions, 8590 Romanshorn, Switz., www.geobrugg.com

Levin B, Nosov M (2009) Physics of tsunamis. transl., Springer

Lynett P, Liu PL-F (2011) Simulation of complex tsunami behaviour. Comput Sci Eng Mag 13(4):50-57

Modular gabion systems (2013) Houston TX, USA. www.gabions.net

Onishi, Norimitsu (2011) Japan's seawalls were little security against tsunami. The NY times (13 March 2011), Wikipedia

Scheel HJ (2012) Tsunami protection system. WIPO PCT/IB2012/057458 (19 Dec 2012)

Scheel HJ (2013a) Submarine construction for tsunami and flooding protection, for fish farming, and for protection of buildings in the sea. Eur Pat Appl EP 13162698 (8 April 2013)

Scheel HJ (2013b) Sea-gabion walls for tsunami and flooding protection, for fish farming, and for protection of buildings in the sea. WIPO PCT/IB2013/055276 (27 June 2013)

Strusinska A (2011) Hydraulic performance of an impermeable submerged structure for tsunami damping. PhD thesis 2010. IBIDEM-Verlag Stuttg, Germany

Tarmey C, Hallyburton R (2004) Seaeye ROV uses CDL inertial navigation for tunnel survey. Sea Technol Mag 45(12):21-26

WHOI (2012) Woods hole oceanographic institution: www.whoi.edu/main/auvs 